\title{
Heritability and genetic etiology of habitual physical activity: a twin study with objective measures
}

\author{
M. Gielen · M. S. Westerterp-Plantenga - F. G. Bouwman • \\ A. M. C. P. Joosen - R. Vlietinck - C. Derom - M. P. Zeegers · \\ E. C. M. Mariman · K. R. Westerterp
}

Received: 6 March 2014/ Accepted: 21 June 2014/Published online: 5 July 2014

(C) Springer-Verlag Berlin Heidelberg 2014

\begin{abstract}
Twin studies with objective measurements suggest habitual physical activity (HPA) are modestly to highly heritable, depending on age. We aimed to confirm or refute this finding and identify relevant genetic variants using a candidate gene approach. HPA was measured for 14 days with a validated triaxial accelerometer (Tracmor) in two populations: (1) 28 monozygotic and 24 dizygotic same-sex twin pairs (aged $22 \pm 5$ years, BMI $21.8 \pm$ $3.4 \mathrm{~kg} / \mathrm{m}^{2}, 21$ male, 31 female pairs); (2) 52 and 65 unrelated men and women (aged $21 \pm 2$ years, BMI $22.0 \pm$ $2.5 \mathrm{~kg} / \mathrm{m}^{2}$ ). Single nucleotide polymorphisms (SNPs) in PPARD, PPARGCIA, NRF1 and MTOR were considered candidates. Association analyses were performed for both groups separately followed by meta-analysis. Structural equation modeling shows significant familiality for HPA, consistent with a role for additive genetic factors (heritability $57 \%, 95 \%$ CI 32-74\%, AE model) or common environmental factors $(47 \%, 95 \%$ CI $23-65 \%$, CE model). A moderate heritability was observed for the time spent on low- and high-intensity physical activity $(P \leq 0.05)$, but could not be confirmed for the time spent
\end{abstract}

\section{Gielen · M. P. Zeegers}

Department of Complex Genetics, Cluster of Genetics and Cell Biology and Nutrition and Toxicology Research Institute Maastricht (NUTRIM), Maastricht University Medical Centre, 6200 MD Maastricht, The Netherlands

M. S. Westerterp-Plantenga - F. G. Bouwman ·

A. M. C. P. Joosen - E. C. M. Mariman $(\varangle) \cdot$ K. R. Westerterp Department of Human Biology, Maastricht University Medical Centre, P.O. Box 616, 6200 MD Maastricht, The Netherlands e-mail: e.mariman@maastrichtuniversity.nl

R. Vlietinck · C. Derom

Department for Human Genetics, Faculty of Medicine, Catholic University of Leuven, 3000 Louvain, Belgium on moderate-intensity physical activity. For PPARD, each additional effect allele was inversely associated with HPA $(P \leq 0.01 ; r s 2076168$ allele $C)$ or tended to be associated with HPA $(P \leq 0.05$; $r s 2267668$ allele $G)$. Linkage disequilibrium existed between those two SNPs (alleles A/G and $\mathrm{A} / \mathrm{C}$, respectively) and meta-analysis showed that carriers of the $A A G C$ haplotype were less physically active than carriers of the $A A A A$ and $A A A C$ haplotypes combined $(P=0.017)$. For PPARGC1A, carriers of $A A$ in $r s 8192678$ spent more time on high-intensity physical activity than $G G$ carriers $(P=0.001)$. No associations were observed with SNPs in NRF1 and MTOR. In conclusion, HPA may be modestly heritable, which is confirmed by an association with variants in PPARD.

Keywords Physical activity - Mitochondrial biogenesis . PPARD · PGC1A · Triaxial accelerometry

\section{Introduction}

Activity-related energy expenditure is the most variable component of total energy expenditure (Ravussin and Swinburn 1992) and an important determinant of energy balance (Schoeller et al. 1997). As such, a reduced level of habitual physical activity (HPA) is a potentially important contributor to the development of obesity (Ekelund et al. 2002; Weinsier et al. 1998). Moreover, a low level of HPA is an independent risk factor for developing type 2 diabetes (Hu et al. 2003), cardiovascular diseases (Fang et al. 2003) and osteoporosis (Neville et al. 2002), as well as for mortality (Hu et al. 2004).

Regardless of the fact that physical activity is known to promote health and despite efforts to promote physical activity in the population, only up to $5 \%$ of the US adult 
population with normal weight achieves the current recommendation of at least $30 \mathrm{~min}$ of moderate-intensity physical activity on 5-7 days of the week (Tudor-Locke et al. 2010). Comparable figures for an European population showed about $50 \%$ achieving the activity guidelines (den Hoed et al. 2013). This may be explained by an intrinsic biological component in physical activity regulation. In fact, evidence from twin studies with objective measures of physical activity suggests a minor genetic effect in children (Fisher et al. 2010), a high level of heritability $\left(h^{2}=78 \%\right)$ in young adults (Joosen et al. 2005), whereas a heritability of $35 \%$ was estimated in a large sample of women ranging from 18 to 80 years of age (den Hoed et al. 2013). Studies aiming to identify genetic variants that are associated with objective measures of HPA are scarce (Cai et al. 2006).

We showed earlier that within the range of normal daily life activities, HPA correlates positively with markers of mitochondrial capacity (den Hoed et al. 2008). As $25-50 \%$ of the variation in capacity of regulatory enzymes of the Kreb's cycle can be explained by genetic variation (Bouchard et al. 1986), single nucleotide polymorphisms (SNPs) in genes encoding proteins involved in mitochondrial biogenesis and energy metabolism were considered candidates for HPA. Peroxisome proliferator-activated receptor (PPAR) $\gamma$ co-activator $1 \alpha$ (PGC-1 $\alpha)$, PPAR $\delta$, nuclear respiratory factor (NRF) 1 and mammalian target of rapamycin (mTOR) are such proteins. In the gene for PGC-1 $\alpha$, the genotypes of SNP rs8192678 were shown to be associated with physical fitness in sedentary subjects (Franks et al. 2003). For PPAR $\delta, C$ allele carriers of SNP rs2076168 had lower mRNA levels possibly leading to lower mitochondrial capacity (Nilsson et al. 2007), whereas also in case of G-carriers for SNP rs2267668, there were indications for a lower mitochondrial capacity (Stefan et al. 2007). SNP rs1882094 in the gene for NRF1 is associated with energy metabolism because GG genotype carriers have significantly lower fasting plasma glucose levels than carriers of the other genotypes (Liu et al. 2008). Based on those previous reports, we selected the same SNPs for testing in the present study. As for mTOR, Schieke et al. (2006) showed that the mTOR-raptor complex directly associates with the mitochondria and that its disruption reduces the oxidative capacity of the cell, which reflects intrinsic mitochondrial properties. Cunningham et al. (2007) showed that treating mTOR with rapamycin, a specific mTOR inhibitor, suppresses the expression of many mitochondrial genes that are induced by PGC- $1 \alpha$. Apparently, mTOR controls mitochondrial gene expression by altering the physical interaction between PGC- $1 \alpha$ and YY1, a transcription factor that binds directly to mitochondrial gene promoters. Since there is no reported association between a SNP in the mTOR gene and metabolic or mitochondrial phenotypes, we selected a SNP, rs11121691, in the coding region of the gene with a sufficiently high minor allele frequency to allow the detection of genetic association.

The present study aimed to (1) confirm or refute the heritability of HPA as measured objectively using a triaxial accelerometer; (2) examine the heritability of intensity and duration of activities performed; (3) assess whether genetic variants in the PPARD, PPARGC1A (encoding PGC- $1 \alpha$ ), $N R F 1$ and MTOR genes are associated with HPA as well as with the intensity and duration of the activities performed. To achieve our goals, we made use of young adult Caucasian twins and compared the concordances between mono- and dizygotic twins. This indicated the contribution of genetic factors in an additive way to the observed traits, which was further studied in detail looking at univariate variance estimates under the assumption of various models, i.e., additive or dominant genetic and common or unique environmental influences. A group of unrelated individuals was included to add to the power of the association study.

\section{Materials and methods}

\section{Participants}

Two healthy, independent populations were studied as follows: (1) a group of 51 same-sex twin pairs and one same-sex (male) triplet (16 monozygotic (MZ) female, 15 dizygotic (DZ) female, $13 \mathrm{MZ}$ male and $8 \mathrm{DZ}$ male pairs (aged $22 \pm 5$ years, BMI $21.8 \pm 3.4 \mathrm{~kg} / \mathrm{m}^{2}$ (mean \pm SD)); (2) a group of 117 unrelated adults of similar age and BMI (65 women, 52 men, aged $21 \pm 2$ years, BMI $22.0 \pm 2.5 \mathrm{~kg} / \mathrm{m}^{2}$ ). Thirty-five twin pairs as well as the triplet were contacted and recruited by the East-Flanders Prospective Twin Survey (EFPTS) (Derom et al. 2006). The remaining sixteen pairs were recruited earlier by Joosen et al. (2005). All participants were from Western European descent and had been weight stable for at least 6 months prior to the study. The study conformed to the standards set by the Declaration of Helsinki as revised in 2000 and the local Ethics Committee approved the study. All participants provided written informed consent before participating.

\section{Habitual physical activity}

Habitual physical activity, as well as the intensity and duration of the activities performed, was measured using a triaxial accelerometer for movement registration (Tracmor IV; Philips research, Eindhoven, The Netherlands). The Tracmor registers accelerations of the trunk along the anterio-posterior, medio-lateral and longitudinal axis using 
three uniaxial piezoelectric accelerometers (details are provided elsewhere (Plasqui et al. 2005)). To ensure a valid reflection of long-term daily life activities, the accelerometer was worn for 14 days under free-living conditions. Participants wore the accelerometer from the moment they woke up in the morning until they went back to bed at night. HPA was subsequently acquired by summing the output of all three axes and is presented as megacounts per day (Mcnts/d). Using accelerometer data, the time spent on low-, moderate- and high-intensity physical activity was determined in min/day. The cutoff points for the intensity categories corresponded with walking at $3.5 \mathrm{~km} / \mathrm{h}$ and $5 \mathrm{~km} / \mathrm{h}$, respectively. To make sure that only representative days were included, the difference between the total time the participant was awake and the time the accelerometer was worn was not allowed to exceed 75 min per day (den Hoed and Westerterp 2008). Thus, data were available for 10-14 days for each subject.

The Tracmor has been validated with doubly labeled water (Plasqui et al. 2005). Using linear regression analysis in a population similar to that of the present study with respect to HPA, body composition and age, the physical activity level (PAL) (average daily metabolic rate/resting metabolic rate) could be predicted with an explained variance of $70 \%$ using Tracmor output only (Plasqui et al. 2005). This regression equation was used in the present study to estimate PAL. The Tracmor provides an objective measure for the total level of physical activity in daily life, as well as of the intensity and duration of the activities performed.

\section{Body composition}

In unrelated participants, body mass was measured to the nearest $0.01 \mathrm{~kg}$ (ID 1 Plus, Mettler, Toledo, Giessen, Germany) and height to the nearest $0.1 \mathrm{~cm}$ (Mod. 220, SECA. Hamburg, Germany). In twins, body mass was measured to the nearest $0.1 \mathrm{~kg}$ (HF380, Philips, Eindhoven, The Netherlands) and height to the nearest $0.1 \mathrm{~cm}$ using a tape measure. \% BF was determined using deuterium dilution according to Siri's three compartment model (Siri 1993). All instruments were calibrated and operated by experienced personnel.

\section{DNA isolation and SNP genotyping}

Genomic DNA was isolated from peripheral blood leukocytes (unrelated participants) using the QIAamp blood kit and from mouth swabs and/or placental tissue collected at birth (twins) using the DNA minikit (Qiagen, Amsterdam, The Netherlands). Candidate SNPs were selected in PPARD, PPARGC1A, MTOR and NRF1 with a minor allele frequency in Europeans of at least $10 \%$ as indicated by the SNP public database (dbSNP; http://www.ncbi.nlm. nih.gov/SNP). The latter cutoff was applied to ensure an ample number of individuals were homozygous for the minor allele. To limit the number of tests and increase the likelihood of finding a true association, only tag SNPs or SNPs that were associated earlier with relevant traits like mRNA or protein level, BMI or maximal oxygen uptake were selected. This resulted in the selection of five SNPs representing four genes (rs2267688 and rs2076168 (PPARD), rs8192678 (PPARGC1A), rs11121691 (MTOR) and rs1882094 (NRF1)).

Genotyping was performed using commercially available TaqMan SNP genotyping assays from Applied Biosystems (Foster City, California, USA). The procedure was performed according to the manufacturer's protocol and measured on an Applied Biosystems 7900 HT Fast RealTime PCR System. Allelic calls were determined semiautomatically using the allelic discrimination software of Applied Biosystems.

Statistical analysis

\section{Descriptive statistical analysis}

The time spent on low-, moderate- and high-intensity physical activity was natural log transformed to achieve a normal distribution of the residuals. Differences in (ln transformed) means between male and female $\mathrm{MZ}$ twins, DZ twins and unrelated individuals, between unrelated individuals and twins (MZ and DZ twins combined), between MZ and DZ twins (separately for men and women) and between the first- and second-born twins were tested with an unpaired $t$ test (two-tailed). Differences were considered significant if $P \leq 0.05$. Results are presented as mean \pm SD for all normally distributed variables and as median and inter-quartile range for the time spent on low-, moderate- and high-intensity physical activity.

A $\chi^{2}$ test with one degree of freedom was used to check whether the allele frequencies were in Hardy-Weinberg equilibrium for both groups separately. In twin pairs, one twin was randomly selected per pair for this analysis. The triplet was randomly included in the heritability analysis as a DZ male pair, and as a DZ male pair and one solitary individual in the association analyses.

\section{Heritability analysis}

Pearson's intra-pair correlation coefficient $(r)$ for objectively measured physical activity traits was compared between MZ and DZ pairs. If $r=0$ for MZ and for DZ pairs, all variance of the trait can be explained by unique environmental factors. If $r$ is larger than zero but equal for $\mathrm{MZ}$ and DZ pairs, then common environmental factors play 
a role as well. A larger $r$ for MZ compared with DZ pairs suggests that additive genetic factors account for at least some of the variance of the trait, whereas an $r$ that is more than twice as high in MZ compared with DZ twins suggests that nonadditive or dominant genetic factors may also play a role.

Structural equation modeling was used to decompose phenotypic variance in physical activity traits into additive genetic (A, additive effects of variants from independent loci), common environmental (C, environmental effects shared by twins reared in the same family) and unique environmental effects (E, environmental effects unique to the individual) (ACE model) using $\mathrm{Mx}$ software (Neale et al. 2006). If the within-pair Pearson correlation coefficient in MZ pairs was (greater than) twice that of DZ pairs, a nonadditive or dominant genetic (D) contribution was additionally considered (ADE model).

To test whether genetic and environmental factors influenced the trait to the same degree in men and women, the unstandardized path coefficients were first tested for equality in men and women. Alternative univariate nested models (ACE, AE, CE and E model) with sex and age as covariates were subsequently fit to the raw data. When appropriate, ACE models were also compared with ADE models. All models were compared using a maximum likelihood approach with accompanying Akaike's information criterion (AIC) (Neale and Cardon 1992). The model with the lowest AIC reflects the most parsimonious model, in which the pattern of variances and covariances is explained by the least number of measurements. The goodness of fit of the nested models was additionally examined using hierarchical $\chi^{2}$ tests. When comparing the fit of non-nested models, that is, ADE and ACE, the model with the lowest AIC was preferred.

\section{Association analyses}

Before the association analyses were performed, associations with potential covariates (sex, age and daylight hours as a proxy for the season of measurement) were examined for HPA as well as for the time spent on low-, moderateand high-intensity physical activity. Zygosity was additionally taken into account in the twins. Covariates were incorporated in the model when $P \leq 0.05$. Associations of physical activity traits and SNPs were examined under an additive model. SNP * SNP interactions were examined by adding a product term to the model.

In the twins, multilevel regression analyses (proc mixed) were performed, taking clustering of the twin pairs into account by adding a random effect to the model. The variance-covariance structure was allowed to differ between MZ and DZ pairs (SAS package version 9.1, SAS Institute Inc., Cary, NC, USA). In the unrelated participants, (multiple) linear regression was used (SPSS version 13 for Macintosh OS X, SPSS Inc.; Chicago, Illinois, USA).

Linkage disequilibrium (LD) was examined for the two SNPs in PPARD using Haploview (Barrett et al. 2005). Haplotypes were estimated using PHASE (Stephens et al. 2001). For MZ pairs, one twin was randomly selected per pair. Haplotype analyses were subsequently performed in SAS using multilevel analyses (proc mixed) (twins) or linear regression analyses (unrelated individuals), analog to the genotype analyses mentioned earlier. Multiple testing was taken into account, and a $P$ value of $\leq 0.0125(0.05 / 4)$ was considered statistically significant; a $P$ value of $\leq 0.10$ was regarded as a trend.

After performing genotype and haplotype analyses for both groups separately, the genotype specific betas of twins and unrelated participants were pooled in a fixed effects meta-analysis using STATA (http://www.stata.com/).

\section{Results}

\section{Descriptive analyses}

HPA as well as the intensity and duration of the activities performed were similar in men and women in MZ twins, DZ twins and unrelated individuals, except for unrelated women spending more time on moderate-intensity physical activity than unrelated men (Table 1). The total level of HPA was not different between the twins and unrelated individuals in either men or women. PAL ranged from 1.5 to 2.2 in both twins and unrelated individuals. In both sexes, the unrelated individuals had a lower \%BF than the twins (MZ and DZ twins combined). Unrelated men spent more time on high-intensity physical activity than male twins, whereas unrelated women spent more time on moderate- and high-intensity physical activity compared with female twins (Table 1).

In the twins, no differences in physical activity or anthropometric traits were observed by birth order $(P>0.10)$. Furthermore, physical activity-related traits were not different between $\mathrm{MZ}$ and $\mathrm{DZ}$ twins in either men or women. Anthropometric traits were also similar between $\mathrm{MZ}$ and $\mathrm{DZ}$ twins, except for $\mathrm{DZ}$ men having a lower \%BF than MZ men. DZ men were also younger than MZ men (Table 1).

Pearson's intra-pair correlation coefficient for HPA was higher in MZ than in DZ pairs $(r=0.64$ vs. $r=0.36$ ), suggesting that additive genetic factors contribute to the inter-individual variation in HPA. For the time spent on low-, moderate- and high-intensity physical activity, dominant genetic factors may also play a role (Table 2). 
Table 1 Descriptive characteristics of unrelated individuals and twins

\begin{tabular}{|c|c|c|c|c|c|c|}
\hline & \multicolumn{2}{|c|}{ Unrelated individuals } & \multicolumn{2}{|l|}{$\begin{array}{l}\text { Twins MZ } \\
29 \text { Pairs }\end{array}$} & \multicolumn{2}{|c|}{$\begin{array}{l}\text { Twins DZ } \\
22 \text { Pairs, } 1 \text { triplet }\end{array}$} \\
\hline & Men & Women & Men & Women & Men & Women \\
\hline$N$ & 52 & 65 & 26 & 32 & 17 & 30 \\
\hline Age (years) & $21 \pm 2$ & $21 \pm 2^{\mathrm{bb}}$ & $23 \pm 5$ & $24 \pm 7$ & $20 \pm 2^{\mathrm{dd}}$ & $22 \pm 2^{\mathrm{aa}}$ \\
\hline Body mass (kg) & $76.0 \pm 10.1$ & $63.4 \pm 7.9^{\text {aaa }}$ & $72.9 \pm 10.7$ & $63.7 \pm 12.5^{\mathrm{aa}}$ & $71.7 \pm 14.2$ & $61.1 \pm 8.5^{\mathrm{aa}}$ \\
\hline Height (m) & $1.85 \pm 0.06$ & $1.70 \pm 0.06^{\text {aaa }}$ & $1.81 \pm 0.09$ & $1.69 \pm 0.07^{\text {aaa }}$ & $1.82 \pm 0.05$ & $1.69 \pm 0.06^{\mathrm{aaa}}$ \\
\hline BMI $\left(\mathrm{kg} / \mathrm{m}^{2}\right)$ & $22.3 \pm 2.4$ & $21.8 \pm 2.6$ & $22.2 \pm 2.7$ & $22.2 \pm 4.6$ & $21.4 \pm 3.4$ & $21.4 \pm 2.6$ \\
\hline$\% \mathrm{BF}$ & $14.8 \pm 6.1^{\mathrm{c}}$ & $26.8 \pm 4.9^{\mathrm{aaa}, \mathrm{bb}}$ & $21.3 \pm 6.2$ & $29.7 \pm 8.9^{\text {aaa }}$ & $15.9 \pm 6.8^{\mathrm{d}}$ & $29.6 \pm 6.2^{\text {aaa }}$ \\
\hline HPA (Mcnts/day) & $3,761 \pm 813$ & $3,796 \pm 718$ & $3,862 \pm 965$ & $3,804 \pm 1,152$ & $3,884 \pm 1,058$ & $3,520 \pm 842$ \\
\hline PAL & $1.82 \pm 0.13$ & $1.83 \pm 0.12$ & $1.84 \pm 0.16$ & $1.83 \pm 0.19$ & $1.84 \pm 0.17$ & $1.78 \pm 0.14$ \\
\hline Low (min/day) & $1,403(20)$ & $1,400(20)^{\mathrm{bb}}$ & $1,393(28)$ & $1,405(27)$ & $1,409(21)$ & $1,412(21)$ \\
\hline $\operatorname{Mod}(\min /$ day) & 27 (13) & $30(15)^{\mathrm{a}, \mathrm{bb}}$ & $38(22)$ & $25(18)$ & 25 (14) & $22(16)$ \\
\hline $\operatorname{High}(\min /$ day $)$ & $9(11)^{\mathrm{c}}$ & $8(8)^{b}$ & $5(8)$ & $7(8)$ & $4(8)$ & $4(5)$ \\
\hline
\end{tabular}

$M Z$ monozygotic; $D Z$ dizygotic; $\% B F$ percentage body fat; $H P A$ habitual physical activity as measured with a triaxial accelerometer for a period of 2 weeks; Mcnts megacounts; PAL physical activity level estimated based on HPA (Plasqui et al. 2005)

Low, Mod and high, time participants were physically active at a low-, moderate- and high-intensity, respectively; values are mean \pm SD [median (interquartile range) for \%low, \% moderate and \%high]. Differences were examined using Student's $t$ tests

a/aa/aaa Significant sex difference (within unrelated individuals, MZ twins, DZ twins), $P \leq 0.05 / P \leq 0.01 / P \leq 0.0001$

b/bb Significantly different from female twins (MZ and DZ combined), $P \leq 0.05 / P \leq 0.01$

c/cc Significantly different from male twins (MZ and DZ combined), $P \leq 0.05 / P \leq 0.01$

d/dd Significantly different from MZ men, $P \leq 0.05 / P \leq 0.01$

Table 2 Intrapair Pearson's correlation coefficients $(r)$ in monozygotic (MZ) and dizygotic (DZ) twins

\begin{tabular}{llllll}
\hline Zygosity & $\mathrm{MZ}$ & & \multicolumn{2}{l}{$\mathrm{DZ}$} \\
\cline { 2 - 3 } \cline { 5 - 6 } Trait & $r$ & $p$ & & $r$ & $p$ \\
\hline HPA & 0.64 & 0.0003 & & 0.36 & 0.08 \\
Low & 0.62 & 0.0004 & & 0.12 & 0.58 \\
Moderate & 0.60 & 0.0008 & & 0.10 & 0.65 \\
High & 0.63 & 0.0003 & & 0.06 & 0.79
\end{tabular}

HPA Habitual physical activity; Low, Moderate, High the time spent on low-, moderate- and high-intensity physical activity, respectively $(\mathrm{min} /$ day $)$

\section{Structural equation modeling}

Intrapair differences in $\mathrm{MZ}$ twins are due to environmental factors and measurement errors ( $\mathrm{C}$ and $\mathrm{E}$ ), whereas intrapair differences in DZ twins are additionally affected by genetic factors (A). To separate the additive genetic (A, additive effects of variants from independent loci), common environmental $(\mathrm{C}$, environmental effects shared by twins reared in the same family) and unique environmental effects (E, environmental effects unique to the individual), structural equation modeling was performed comparing the covariances of MZ twins with DZ twins.

For HPA, as well as for the time spent on moderate- and high-intensity physical activity, the unstandardized additive genetic path coefficients were equal in men and women. For the time spent on low-intensity physical activity, the additive genetic path coefficients were different in men and women. Hence, both sexes were analyzed separately for the latter trait.

\section{Habitual physical activity}

For HPA, the AE model was the most parsimonious model, with additive genetic factors explaining $57 \%(95 \%$ CI $32-74 \%$ ) of the inter-individual variation in HPA (Table 3). However, the $\mathrm{AE}$ and $\mathrm{CE}$ models were not significantly different from each other and only the $\mathrm{E}$ model, in which all inter-individual variation is explained by unique environmental factors, was rejected.

\section{Low-intensity physical activity}

The contribution of additive genetic factors to the time spent on low-intensity physical activity was lower in men than in women [38\% (95\% CI $18-59 \%)$ vs. $72 \%(95 \%$ CI 40-87\%), respectively], due to a lower un-standardized unique environmental path coefficient in women than in men. For the time spent on low-intensity physical activity, the CE and $\mathrm{E}$ models were rejected. The $\mathrm{AE}$ model was most parsimonious, although a scenario in which dominant genetic factors also play a role could not be excluded (Table 3 ). 
Table 3 Univariate variance estimates of additive genetic (A), dominant genetic (D), common environmental (C) and unique environmental (E) contributions to habitual physical activity and the intensity and duration of the activities performed

\begin{tabular}{|c|c|c|c|c|c|c|c|c|c|c|c|c|c|}
\hline \multirow{2}{*}{ HPA } & \multicolumn{13}{|c|}{ Model fit } \\
\hline & \multirow{2}{*}{$\begin{array}{l}\mathrm{A} \\
0.54\end{array}$} & \multicolumn{2}{|c|}{$95 \%$ CI } & $\mathrm{D}$ & \multicolumn{2}{|c|}{$95 \%$ CI } & $\mathrm{C}$ & \multicolumn{2}{|c|}{$95 \%$ CI } & $\mathrm{E}$ & \multicolumn{2}{|c|}{$95 \% \mathrm{CI}$} & AIC \\
\hline ACE & & 0.00 & 0.74 & - & - & - & 0.03 & 0.00 & 0.61 & 0.43 & 0.26 & 0.70 & 83.11 \\
\hline $\mathrm{AE}$ & 0.57 & 0.32 & 0.74 & - & - & - & - & - & - & 0.43 & 0.26 & 0.69 & 81.12 \\
\hline $\mathrm{CE}$ & - & - & & - & - & - & 0.47 & 0.23 & 0.65 & 0.53 & 0.35 & 0.77 & 82.84 \\
\hline $\mathrm{E}$ & - & - & & - & - & - & - & - & - & 1 & - & - & 94.03 \\
\hline \multicolumn{14}{|l|}{ Low } \\
\hline \multicolumn{14}{|l|}{$\mathrm{ACE}$} \\
\hline Male & 0.38 & 0.11 & 0.38 & - & - & - & 0.00 & 0.00 & 0.05 & 0.62 & 0.62 & 0.82 & -817.92 \\
\hline Female & 0.72 & 0.22 & 0.72 & - & - & - & 0.00 & 0.00 & 0.08 & 0.28 & 0.13 & 0.60 & \\
\hline \multicolumn{14}{|l|}{$\mathrm{AE}$} \\
\hline Male & 0.38 & 0.18 & 0.59 & - & - & - & - & - & - & 0.62 & 0.41 & 0.82 & -819.92 \\
\hline Female & 0.72 & 0.40 & 0.87 & - & - & - & - & - & - & 0.28 & 0.13 & 0.60 & \\
\hline \multicolumn{14}{|l|}{$\mathrm{CE}$} \\
\hline Male & - & - & - & - & - & - & 0.24 & 0.07 & 0.46 & 0.76 & 0.54 & 0.93 & -813.94 \\
\hline Female & - & - & - & - & - & - & 0.43 & 0.14 & 0.66 & 0.57 & 0.34 & 0.86 & \\
\hline \multicolumn{14}{|l|}{$\mathrm{E}$} \\
\hline Male & - & - & - & - & - & - & - & - & - & 1 & - & - & -804.99 \\
\hline Female & - & - & - & - & - & - & - & - & - & 1 & - & - & \\
\hline \multicolumn{14}{|l|}{$\mathrm{ADE}$} \\
\hline Male & 0.00 & 0.00 & 0.54 & 0.38 & 0.00 & 0.58 & - & - & - & 0.62 & 0.42 & 0.80 & -819.58 \\
\hline Female & 0.00 & 0.00 & 0.84 & 0.74 & 0.00 & 0.87 & - & - & - & 0.26 & 0.15 & 0.54 & \\
\hline \multicolumn{14}{|l|}{ Moderate } \\
\hline $\mathrm{ACE}$ & 0.55 & 0.00 & 0.73 & - & - & - & - & 0.00 & 0.59 & 0.45 & 0.27 & 0.70 & -34.36 \\
\hline $\mathrm{AE}$ & 0.55 & 0.30 & 0.73 & - & - & - & - & - & - & 0.45 & 0.27 & 0.70 & -34.36 \\
\hline $\mathrm{CE}$ & - & - & - & - & - & - & 0.46 & 0.22 & 0.64 & 0.54 & 0.36 & 0.78 & -34.29 \\
\hline $\mathrm{E}$ & - & - & - & - & - & - & - & - & - & 1 & - & - & -23.52 \\
\hline $\mathrm{ADE}$ & 0.27 & 0.00 & 0.72 & 0.29 & 0.00 & 0.73 & - & - & - & 0.44 & 0.27 & 0.70 & -34.44 \\
\hline \multicolumn{14}{|l|}{ High } \\
\hline ACE & 0.47 & 0.00 & 0.72 & - & - & - & 0.00 & 0.00 & 0.30 & 0.53 & 0.28 & 0.88 & 38.48 \\
\hline $\mathrm{AE}$ & 0.47 & 0.12 & 0.72 & - & - & - & - & - & - & 0.53 & 0.28 & 0.88 & 36.48 \\
\hline $\mathrm{CE}$ & - & - & - & - & - & - & 0.23 & 0.00 & 0.47 & 0.77 & 0.53 & 1.00 & 40.28 \\
\hline $\mathrm{E}$ & - & - & - & - & - & - & - & - & - & 1 & - & - & 41.30 \\
\hline $\mathrm{ADE}$ & 0.00 & 0.00 & 0.65 & 0.55 & 0.00 & 0.74 & - & - & - & 0.45 & 0.26 & 0.79 & 36.34 \\
\hline & & Com & ed wit & $\mathrm{CE} \mathrm{m}$ & del & & & & & & & & \\
\hline & & $-2 \mathrm{~L}$ & & & $d f$ & & $\Delta \chi^{2}$ & & $d f$ & & $\Delta \mathrm{AIC}$ & & $P$ value \\
\hline HPA & & & & & & & & & & & & & \\
\hline ACE & & & & & 102 & & - & & - & & - & & - \\
\hline $\mathrm{AE}$ & & & & & 103 & & 0.00 & & 1 & & -2.00 & & 0.95 \\
\hline $\mathrm{CE}$ & & & & & 103 & & 1.74 & & 1 & & -0.26 & & 0.19 \\
\hline $\mathrm{E}$ & & & & & 104 & & 14.92 & & 2 & & 10.92 & & 0.001 \\
\hline Low & & & & & & & & & & & & & \\
\hline $\mathrm{ACE}$ & & & & & & & & & & & & & \\
\hline Male & & -61 & & & 101 & & - & & - & & - & & - \\
\hline Female & & & & & & & & & & & & & \\
\hline
\end{tabular}


Table 3 continued

\begin{tabular}{|c|c|c|c|c|c|c|}
\hline & \multicolumn{6}{|c|}{ Compared with ACE model } \\
\hline & $-2 \mathrm{LL}$ & $d f$ & $\Delta \chi^{2}$ & $d f$ & $\Delta \mathrm{AIC}$ & $P$ value \\
\hline \multicolumn{7}{|l|}{$\mathrm{AE}$} \\
\hline Male & -615.92 & 102 & 0 & 1 & -2.00 & 1 \\
\hline \multicolumn{7}{|c|}{ Female } \\
\hline \multicolumn{7}{|l|}{$\mathrm{CE}$} \\
\hline Male & -609.94 & 102 & 5.99 & 1 & 3.99 & 0.01 \\
\hline \multicolumn{7}{|c|}{ Female } \\
\hline \multicolumn{7}{|l|}{$\mathrm{E}$} \\
\hline Male & -596.99 & 103 & 18.94 & 3 & 12.94 & 0 \\
\hline \multicolumn{7}{|c|}{ Female } \\
\hline \multicolumn{7}{|l|}{$\mathrm{ADE}$} \\
\hline Male & -617.58 & 101 & - & - & - & - \\
\hline \multicolumn{7}{|c|}{ Female } \\
\hline \multicolumn{7}{|c|}{ Moderate } \\
\hline ACE & 169.64 & 102 & - & - & - & - \\
\hline $\mathrm{AE}$ & 169.64 & 103 & 0 & 1 & -2.00 & 1 \\
\hline $\mathrm{CE}$ & 171.71 & 103 & 2.07 & 1 & 0.07 & 0.15 \\
\hline $\mathrm{E}$ & 184.49 & 104 & 14.85 & 2 & 10.85 & 0.001 \\
\hline $\mathrm{ADE}$ & 169.56 & 102 & - & - & - & - \\
\hline \multicolumn{7}{|l|}{ High } \\
\hline ACE & 242.48 & 102 & & & & \\
\hline $\mathrm{AE}$ & 242.48 & 103 & 0 & 1 & -2.00 & 1 \\
\hline $\mathrm{CE}$ & 246.28 & 103 & 3.80 & 1 & 1.80 & 0.05 \\
\hline $\mathrm{E}$ & 249.30 & 104 & 6.82 & 2 & 2.82 & 0.03 \\
\hline $\mathrm{ADE}$ & 240.34 & 102 & - & - & - & - \\
\hline
\end{tabular}

$\mathrm{A}, \mathrm{D}, \mathrm{C}$ and $\mathrm{E}$, the variance explained by additive and dominant genetic, common and unique environmental variance, respectively; Estimates include sex and age as covariates. HPA habitual physical activity; Low, Moderate and High, time spent on low-, moderate- and high-intensity physical activity, respectively; $-2 L L-2 \log$ likelihood; AIC Akaike's information criterion

\section{Moderate-intensity physical activity}

For the time spent on moderate-intensity physical activity, the ACE, AE, CE and ADE models were equally parsimonious. Only a model in which all variation was explained by unique environmental factors (E) was rejected.

\section{High-intensity physical activity}

For high-intensity physical activity, the $\mathrm{CE}$ and $\mathrm{E}$ models fit the data significantly worse than the ACE model. The $\mathrm{AE}$ and $\mathrm{ADE}$ models were more parsimonious than the ACE model, suggesting heritabilities of $47 \%$ under an AE model $(95 \% 12-72 \%)$ and $55 \%$ under an ADE model (95\% CI 0-74\%) (Table 3).

\section{Genetic association}

All SNPs were in Hardy-Weinberg equilibrium in both populations, except for $r s 1882094$ (NRF1) in the twins
(Table 4). Of the covariates examined (see Table 1 for potential covariates), age contributed significantly to the variation in the time spent on low- and moderate-intensity physical activity in the twins and was therefore taken into account for these phenotypes. No significant SNP * SNP interactions were observed for HPA or the intensity and duration of the activities performed.

\section{PPARD}

Intronic $r s 2267668$ in twins and unrelated participants tended to be associated with HPA $(P<0.050)$ (Fig. 1a, b). Meta-analysis showed that $A G$ and $G G$ carriers were less physically active than $A A$ carriers $(P=0.005$ and $P=0.057, \quad$ respectively) (Table 5). Also, intronic $r s 2076168$ was associated with HPA in twins $(P=0.006)$, whereas a trend toward an association was observed in unrelated participants $(P=0.091)$ (Fig. 1c, d). Meta-analysis showed that $A C$ and $C C$ carriers in rs2076168 tended to be or were less physically active 

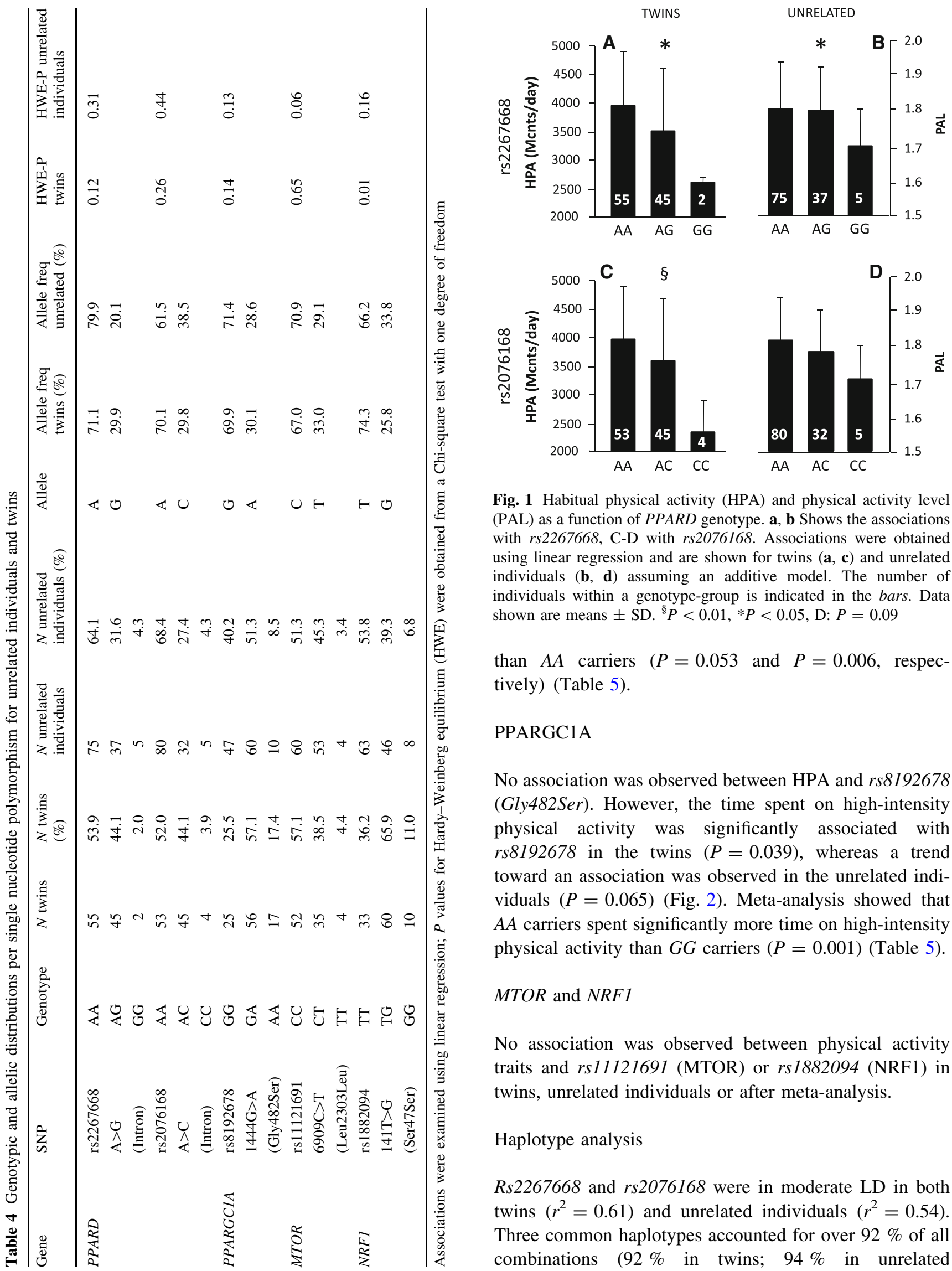

Fig. 1 Habitual physical activity (HPA) and physical activity level (PAL) as a function of PPARD genotype. a, b Shows the associations with $r s 2267668$, C-D with $r s 2076168$. Associations were obtained using linear regression and are shown for twins (a, c) and unrelated individuals (b, d) assuming an additive model. The number of individuals within a genotype-group is indicated in the bars. Data shown are means $\pm \mathrm{SD} .{ }^{\S} P<0.01, * P<0.05, \mathrm{D}: P=0.09$

than $A A$ carriers $(P=0.053$ and $P=0.006$, respectively) (Table 5).

\section{PPARGC1A}

No association was observed between HPA and $r s 8192678$ (Gly482Ser). However, the time spent on high-intensity physical activity was significantly associated with $r s 8192678$ in the twins $(P=0.039)$, whereas a trend toward an association was observed in the unrelated individuals $(P=0.065)$ (Fig. 2). Meta-analysis showed that $A A$ carriers spent significantly more time on high-intensity physical activity than $G G$ carriers $(P=0.001)$ (Table 5).

\section{$M T O R$ and NRF1}

No association was observed between physical activity traits and $r s 11121691$ (MTOR) or $r s 1882094$ (NRF1) in twins, unrelated individuals or after meta-analysis.

Haplotype analysis

$R s 2267668$ and $r s 2076168$ were in moderate LD in both twins $\left(r^{2}=0.61\right)$ and unrelated individuals $\left(r^{2}=0.54\right)$. Three common haplotypes accounted for over $92 \%$ of all combinations $(92 \%$ in twins; $94 \%$ in unrelated 
Table 5 Associations between parameters of habitual physical activity and SNPs in PPARD and PPARGC1A obtained by meta-analysis

\begin{tabular}{|c|c|c|c|c|c|c|}
\hline Phenotype & Gene & SNP & Genotype/Haplotype & Beta & $P$ value & Heterogeneity \\
\hline \multirow[t]{5}{*}{ HPA } & \multirow[t]{2}{*}{ PPARD } & \multirow[t]{2}{*}{$r s 2267668$} & $A G$ & -384.3 & 0.005 & 0.41 \\
\hline & & & $G G$ & -684.6 & 0.057 & 0.15 \\
\hline & \multirow[t]{2}{*}{ PPARD } & \multirow[t]{2}{*}{$r s 2076168$} & $A C$ & -247.5 & 0.053 & 0.68 \\
\hline & & & $C C$ & -801.1 & 0.006 & 0.43 \\
\hline & PPARD & Haplotype & $A A$ and $G C$ & -348.4 & 0.017 & 0.96 \\
\hline \multirow[t]{2}{*}{ High } & \multirow[t]{2}{*}{ PPARGCIA } & \multirow[t]{2}{*}{$r s 8192678$} & $G A$ & -0.139 & 0.27 & \multirow[t]{2}{*}{0.49} \\
\hline & & & $A A$ & 0.671 & 0.001 & \\
\hline
\end{tabular}

HPA, habitual physical activity in Mcnts/day; \%High, the time spent on high-intensity physical activity in min/d; for $r s 2267668$ and $r s 2076168$ in PPARD, AA carriers are the reference group; for the haplotype analysis, $A A A A$ and $A A A C$ haplotype carriers are the reference group; for rs 8192678 in PPARGC1A, GG carriers are the reference group. High was natural log transformed. Heterogeneity refers to the $P$ value of $\mathrm{Q}$ statistic
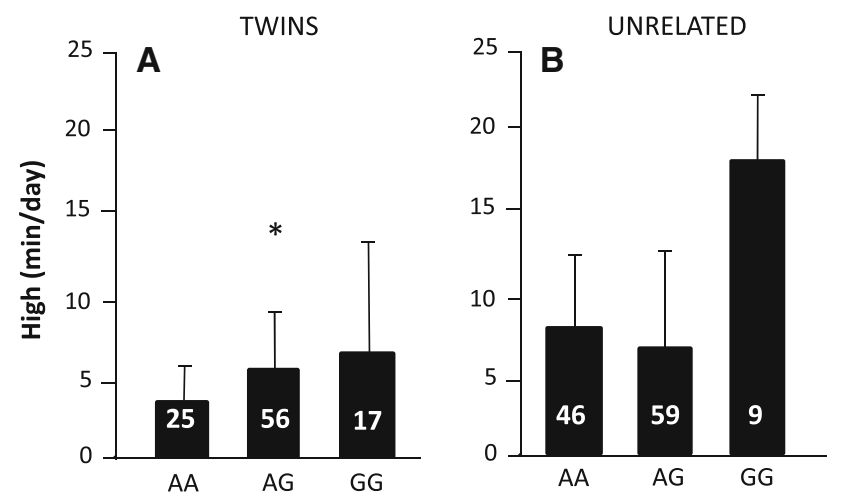

Fig. 2 Time spent on high-intensity physical activity (High) as a function of PPARGC1A genotype. Associations obtained using linear regression are shown for twins (a) and unrelated participants (b) assuming an additive model. The number of individuals within a genotype-group is indicated in the bars. Data shown are median and inter-quartile range. $* P<0.05, \mathbf{b} P=0.06$

participants). In the twins, $47 \%(N=51)$ were $A A$ and $A A, 8 \%(N=9)$ were $A A$ and $A C$ and $37 \%(N=40)$ were $A A$ and $G C$. In the unrelated individuals, $67 \%$ $(N=78)$, were $A A$ and $A A, 10 \%(N=12)$ were $A A$ and $A C$ and $17 \%(N=20)$ were $A A$ and $G C$. HPA tended to be lower in $A A$ and $G C$ haplotype carriers (PAL $=1.78$ in both twins and unrelated individuals) than in the other two haplotypes combined $(\mathrm{PAL}=1.84$ for both haplotype combinations in twins and unrelated individuals) ( $P=0.135$ in twins, $P=0.068$ in unrelated individuals). Meta-analysis showed that $A A$ and $G C$ haplotype carriers tended to be significantly less physically active than carriers of the other two haplotypes combined $(P=0.017)$ (Table 5).

\section{Discussion}

The current study provides evidence for a modest level of heritability for the time spent on low- and high-intensity physical activity and shows that familial resemblance in HPA and the time spent on moderate-intensity activities may reflect either a modest level of heritability or an effect of common environmental factors. Associations of HPA with variants in PPARD, which were observed in two independent samples, are in line with a modest heritability for HPA.

For HPA, the AE model was most parsimonious, suggesting a heritability of $57 \%$. This is lower than the $78 \%$ observed earlier by Joosen et al. (Joosen et al. 2005), but is congruent with the $55 \%$ observed in a twin study with subjective (Mustelin et al. 2009) measures of physical activity, but higher than the $37 \%$ of the twin study with objective measurements (den Hoed et al. 2013). In concordance with earlier studies, the present study suggests that the residual variance (43\%) is likely accounted for by unique environmental factors (AE model) (Cai et al. 2006; Joosen et al. 2005; Mustelin et al. 2009; den Hoed et al. 2013). However, a role for common environmental factors (ACE model) cannot be excluded, as approximately 262 twin pairs are required to detect such an effect with an additive genetic effect of $60 \%$, a confidence level of 0.05 and a power of $80 \%$ (Visscher et al. 2008). A CE model in which variation in HPA is explained by common and unique environmental factors cannot be rejected either. The familial resemblance of HPA could thus also result from common environmental factors. At childhood, the variance may best be explained by (common and unique) environmental factors (Fisher et al. 2010), whereas later in life the influence of common environmental factors has disappeared and genetic factors become more important (den Hoed et al. 2013).

For the time spent on low- and high-intensity physical activity, models only allowing for environmental factors (CE and E) fit the data significantly worse when compared with a model that additionally allowed for an additive genetic contribution (ACE), confirming a heritable component. For low- and high-intensity physical activity, the 
$\mathrm{AE}$ and $\mathrm{ADE}$ models were most, but equally, parsimonious. For the time spent on moderate-intensity physical activity, the ACE, AE, CE and ADE models were equally parsimonious. This implies that a model allowing for common and unique environmental factors (CE) fit the data equally well when compared with a model that allowed for additive genetic and unique environmental factors (AE). Hence, structural equation modeling did not confirm or refute a role of genetic factors for the time spent on moderate-intensity physical activity.

Part of the variance in physical activity-related traits was explained by variants in PPARD (HPA) and PPARGC1A (high-intensity physical activity). PPARGC1A encodes PGC-1 $\alpha$, a transcription factor co-activator that is essential for the transcription of many genes required for the expansion and replication of mitochondria (McCarty 2005). PPAR $\delta$, the predominant PPAR isoform in skeletal muscle, is co-activated by PGC- $1 \alpha$ (Wang et al. 2003). Much like PGC- $1 \alpha$, PPAR $\delta$ regulates fatty acid oxidation via the transcription of genes involved in $\beta$-oxidation and energy uncoupling (Tanaka et al. 2003; Wang et al. 2003). In addition, PPAR $\delta$ is involved in regulating bone turnover (Scholtysek et al. 2013). Altogether, it is clear that both these genes have an essential function in development and performance of the locomotive system.

The $C$ allele in the intronic $r s 2076168$ SNP in PPARD was associated earlier with lower PPAR $\delta$ mRNA levels (Nilsson et al. 2007). AC/CC carriers may thus be genetically predisposed for a lower mitochondrial capacity than $A A$ carriers. In line with this, young $A G / G G$ carriers in the intronic $r 22267668 \mathrm{SNP}$ in PPARD were characterized earlier by a lower mitochondrial capacity in vitro than $A A$ carriers (Stefan et al. 2007). The present study shows that carriers of the $A G / G G$ and $A C / C C$ genotypes in these variants had a lower level of HPA compared with $A A$ carriers. Results from genotype and haplotype analyses were consistent and the associations were stronger after meta-analysis. There was no evidence for heterogeneity of effect size between the two groups, in spite of differences in allele frequencies, body composition, and intensity and duration of the activities performed (Tables 1,4). This suggests that these associations were robust and independent of both measured and unmeasured confounders.

Our group has reported previously a positive association between mitochondrial capacity and HPA and concluded that an active lifestyle may increase mitochondrial capacity (den Hoed et al. 2008). The results from the present study suggest that the latter association may also result from a genetic predisposition, with individuals genetically predisposed for a lower mitochondrial capacity leading a less physically active lifestyle than individuals genetically predisposed for a higher mitochondrial capacity.
Carriers of the GA/AA genotype in $r s 8192678$ (PPARGC1A) spent significantly more time on highintensity physical activity than $G G$ carriers. High-intensity physical activity is known to increase skeletal muscle PGC- $1 \alpha$ protein content (Franks and Loos 2006; Pilegaard et al. 2003), mitochondrial capacity (Tarnopolsky et al. 2007; Tonkonogi and Sahlin 2002) and maximal oxygen uptake (Gavin et al. 2007). Hence, the GA/AA genotypes could be anticipated to reduce the risk for cardiovascular diseases and type 2 diabetes mellitus. However, metaanalysis of results from older individuals previously showed that the odds of having type 2 diabetes increased by $11 \%$ with each additional $A$ allele in $r s 8192678$ (Barroso et al. 2006). Older $A A$ carriers in $r s 8192678$ were also shown to be less physically fit compared with $G G$ carriers when sedentary, but not when physically active (Franks et al. 2003). This suggests that the association between $r s 8192678$ and the risk for developing type 2 diabetes may be modified by physical activity (Franks et al. 2003). Physical activity and, especially, its high-intensity component are known to be lower in the elderly (Meijer et al. 2001). Hence, in young adults, the increased risk for developing type 2 diabetes associated with the $G A / A A$ genotypes in $r s 8192678$ may be compensated for by an increased time spent on high-intensity physical activity (Ling et al. 2004).

An important aspect to consider here is the possibility of geneXenvironment interaction. A review of Lee et al. shows that physical activity is often involved in such complex interactions (Lee et al. 2011). Influence of the genotype on the level or type of physical activity can directly relate to parameters of health such as body composition or risk for cardiovascular defects or type 2 diabetes. Clear examples exist already for PPARGC1A of which the 482Ser allele is associated with increased risk for obesity in elderly men, when they refrain from physical activity (Ridderstrale et al. 2006). On the other hand, obese carriers of this allele seem to have more benefit of dietinduced weight loss with regard to insulin sensitivity (Goyenochea et al. 2008). Our present study points also to the possible involvement of PPARD in such complex interactions with physical activity and parameters of health or risk for disease. This should now be investigated.

Strengths of the present study are the objective measurement of HPA using a validated triaxial accelerometer, its multidisciplinary approach and confirmation of genetic associations in an independent population. Physical activity was measured with a triaxial accelerometer for movement registration (Tracmor). Although every method has its intrinsic limitations, the Tracmor is one of the two most extensively validated accelerometers where the best results were found for the Tracmor as compared with doubly labeled water (Plasqui and Westerterp 2007). Doubly 
labeled water has become the gold standard for the validation of methods of assessing physical activity behavior (Melanson and Freedson 1996). Because of the relatively small sample size, confidence intervals of heritability estimates remain wide. Association studies with larger sample sizes are required to replicate our findings. In this regard, it should be noted that we did not apply multiple testing correction in order to avoid losing information. As can be seen from Tables 4 and 5, all of our significant results have $P$ values $<0.02$, which would remain significant after correcting for testing of the four unrelated polymorphic sites. Although the SNPs analyzed in this study were carefully selected based on the demonstrated relevance of the genes for the proper function of muscle and bone and as such for physical activity, many other genes and their polymorphisms should be investigated as well. This argues for a genome-wide genetic analysis, for which our present study population is too small. Results of such a study may eventually be used to determine physical activity limits in individuals, which could be helpful for career planning or for preventing loss of sufficient physical activity during later life.

In summary, this small scale twin study with objective measurements for physical activity confirms a modest level of heritability for the time spent on low- and high-intensity physical activity and suggests a modest level of heritability for HPA. Variation in the PPARD and PPARGCIA genes contributes to the inter-individual variation in HPA and the time spent on high-intensity physical activity. One pathway shows compliance with a genetic predisposition in PPARD for physiologically limited HPA, another pathway is consistent with a protective effect of high-intensity physical activity for the genetically predisposed development of type 2 diabetes in PPARGC1A.

Acknowledgments The authors appreciate the effort made by the East-Flanders Prospective Twin Survey (EFPTS) to recruit twin pairs. Since its origin, the EFPTS has been partly supported by grants from the Fund of Scientific Research, Flanders and Twins, a nonprofit Association for Scientific Research in Multiple Births (Belgium). We thank Dr. Marcel den Hoed for providing support and advice to execute this study. The experiments were designed by MG, MWP, $\mathrm{CD}, \mathrm{EM}$ and $\mathrm{KW}$; the data were collected by Dr. Marcel den Hoed and $\mathrm{AJ}$; the data were analyzed by MG, FB and MZ; the manuscript was written by MG; significant advice and consultation was provided by MG, MW, FB, AJ, RV, CD, MZ, EM and KW. This study was funded by Maastricht University

Conflict of interest None.

\section{References}

Barrett JC, Fry B, Maller J, Daly MJ (2005) Haploview: analysis and visualization of LD and haplotype maps. Bioinformatics 21(2): 263-265
Barroso I, Luan J, Sandhu MS, Franks PW, Crowley V, Schafer AJ, O'Rahilly S, Wareham NJ (2006) Meta-analysis of the Gly482Ser variant in PPARGC1A in type 2 diabetes and related phenotypes. Diabetologia 49(3):501-505

Bouchard C, Simoneau JA, Lortie G, Boulay MR, Marcotte M, Thibault MC (1986) Genetic effects in human skeletal muscle fiber type distribution and enzyme activities. Can J Physiol Pharmacol 64(9):1245-1251

Cai G, Cole SA, Butte N, Bacino C, Diego V, Tan K, Goring HH, O'Rahilly S, Farooqi IS, Comuzzie AG (2006) A quantitative trait locus on chromosome $18 \mathrm{q}$ for physical activity and dietary intake in Hispanic children. Obesity 14(9):1596-1604

Cunningham JT, Rodgers JT, Arlow DH, Vazquez F, Mootha VK, Puigserver P (2007) mTOR controls mitochondrial oxidative function through a YY1-PGC-1alpha transcriptional complex. Nature 450(7170):736-740

den Hoed M, Westerterp KR (2008) Body composition is associated with physical activity in daily life as measured using a triaxial accelerometer in both men and women. Int $\mathrm{J}$ Obes (Lond) 32(8):1264-1270

den Hoed M, Hesselink MK, van Kranenburg GP, Westerterp KR (2008) Habitual physical activity in daily life correlates positively with markers for mitochondrial capacity. J Appl Physiol 105(2):561-568

den Hoed M, Brage S, Zhao JH, Westgate K, Nessa A, Ekelund U, Spector TD, Wareham NJ, Loos RJ (2013) Heritability of objectively assessed daily physical activity and sedentary behavior. Am J Clin Nutr 98(5):1317-1325. doi:10.3945/ajen. 113.069849

Derom CA, Vlietinck RF, Thiery EW, Leroy FO, Fryns JP, Derom RM (2006) The east flanders prospective twin survey (EFPTS). Twin Res Hum Genet 9(6):733-738

Ekelund U, Aman J, Yngve A, Renman C, Westerterp K, Sjostrom M (2002) Physical activity but not energy expenditure is reduced in obese adolescents: a case-control study. Am J Clin Nutr 76(5): 935-941

Fang J, Wylie-Rosett J, Cohen HW, Kaplan RC, Alderman MH (2003) Exercise, body mass index, caloric intake, and cardiovascular mortality. Am J Prev Med 25(4):283-289

Fisher A, van Jaarsveld CH, Llewellyn CH, Wardle J (2010) Environmental influences on children's physical activity: quantitative estimates using a twin design. PLoS One 5(4):e10110

Franks PW, Loos RJ (2006) PGC-1alpha gene and physical activity in type 2 diabetes mellitus. Exerc Sport Sci Rev 34(4):171-175

Franks PW, Barroso I, Luan J, Ekelund U, Crowley VE, Brage S, Sandhu MS, Jakes RW, Middelberg RP, Harding AH, Schafer AJ, O'Rahilly S, Wareham NJ (2003) PGC-1alpha genotype modifies the association of volitional energy expenditure with [OV0312]O2max. Med Sci Sports Exerc 35(12):1998-2004

Gavin TP, Ruster RS, Carrithers JA, Zwetsloot KA, Kraus RM, Evans CA, Knapp DJ, Drew JL, McCartney JS, Garry JP, Hickner RC (2007) No difference in the skeletal muscle angiogenic response to aerobic exercise training between young and aged men. J Physiol 585(Pt 1):231-239

Goyenochea E, Crujeiras AB, Abete I, Parra D, Martinez JA (2008) Enhanced short-term improvement of insulin response to a low-caloric diet in obese carriers of the Gly482Ser variant of the PGC-1alpha gene. Diabetes Res Clin Pract 82(2): 190-196

Hu G, Qiao Q, Silventoinen K, Eriksson JG, Jousilahti P, Lindstrom J, Valle TT, Nissinen A, Tuomilehto J (2003) Occupational, commuting, and leisure-time physical activity in relation to risk for Type 2 diabetes in middle-aged Finnish men and women. Diabetologia 46(3):322-329

Hu FB, Willett WC, Li T, Stampfer MJ, Colditz GA, Manson JE (2004) Adiposity as compared with physical activity in 
predicting mortality among women. N Engl J Med 351(26):2694-2703. doi:10.1056/NEJMoa042135

Joosen AM, Gielen M, Vlietinck R, Westerterp KR (2005) Genetic analysis of physical activity in twins. Am J Clin Nutr 82(6): 1253-1259

Lee YC, Lai CQ, Ordovas JM, Parnell LD (2011) A database of geneenvironment interactions pertaining to blood lipid traits, cardiovascular disease and type 2 diabetes. J Data Mining Genomics Proteomics 2(1):106

Ling C, Poulsen P, Carlsson E, Ridderstrale M, Almgren P, Wojtaszewski J, Beck-Nielsen H, Groop L, Vaag A (2004) Multiple environmental and genetic factors influence skeletal muscle PGC-1alpha and PGC-1beta gene expression in twins. J Clin Invest 114(10):1518-1526

Liu Y, Niu N, Zhu X, Du T, Wang X, Chen D, Wu X, Gu HF, Liu Y (2008) Genetic variation and association analyses of the nuclear respiratory factor 1 (nRF1) gene in Chinese patients with type 2 diabetes. Diabetes 57(3):777-782

McCarty MF (2005) Up-regulation of PPARgamma coactivator1alpha as a strategy for preventing and reversing insulin resistance and obesity. Med Hypotheses 64(2):399-407

Meijer EP, Goris AH, Wouters L, Westerterp KR (2001) Physical inactivity as a determinant of the physical activity level in the elderly. Int J Obes Relat Metab Disord 25(7):935-939

Melanson EL Jr, Freedson PS (1996) Physical activity assessment: a review of methods. Crit Rev Food Sci Nutr 36(5):385-396. doi:10.1080/10408399609527732

Mustelin L, Silventoinen K, Pietilainen K, Rissanen A, Kaprio J (2009) Physical activity reduces the influence of genetic effects on BMI and waist circumference: a study in young adult twins. Int J Obes (Lond) 33(1):29-36. doi:10.1038/ijo.2008.258

Neale M, Cardon L (1992) Methodology for genetic studies of twins and families. Kluwer Academic, Dordrecht

Neale MC, Broker SM, Xie G, Maes HH (2006) Mx: statistical modeling, 7th edn. Department of Psychiatry, Virginia Commonwealth University, Richmond

Neville CE, Murray LJ, Boreham CA, Gallagher AM, Twisk J, Robson PJ, Savage JM, Kemper HC, Ralston SH, Davey Smith G (2002) Relationship between physical activity and bone mineral status in young adults: the Northern Ireland Young Hearts Project. Bone 30(5):792-798

Nilsson E, Poulsen P, Sjogren M, Ling C, Ridderstrale M, Groop L, Vaag A (2007) Regulation of skeletal muscle PPAR $\{$ delta\} mRNA expression in twins. J Physiol 584(Pt 3):1011-1017

Pilegaard H, Saltin B, Neufer PD (2003) Exercise induces transient transcriptional activation of the PGC-1alpha gene in human skeletal muscle. J Physiol 546(Pt 3):851-858

Plasqui G, Westerterp KR (2007) Physical activity assessment with accelerometers: an evaluation against doubly labeled water. Obesity 15(10):2371-2379. doi:10.1038/oby.2007.281

Plasqui G, Joosen AM, Kester AD, Goris AH, Westerterp KR (2005) Measuring free-living energy expenditure and physical activity with triaxial accelerometry. Obes Res 13(8):1363-1369

Ravussin E, Swinburn BA (1992) Pathophysiology of obesity. Lancet 340(8816):404-408

Ridderstrale M, Johansson LE, Rastam L, Lindblad U (2006) Increased risk of obesity association with the variant allel of the PPARGC1A Gly482Ser polymorphism in physically inactive elderly men. Diabetologia 49(3):496-500

Schieke SM, Phillips D, McCoy JP Jr, Aponte AM, Shen RF, Balaban RS, Finkel T (2006) The mammalian target of rapamycin (mTOR) pathway regulates mitochondrial oxygen consumption and oxidative capacity. J Biol Chem 281(37):27643-27652

Schoeller DA, Shay K, Kushner RF (1997) How much physical activity is needed to minimize weight gain in previously obese women? Am J Clin Nutr 66(3):551-556

Scholtysek C, Katzenbeisser J, Fu H, Uderhardt S, Ipseiz N, Stoll C, Zaiss MM, Stock M, Donhauser L, Bohm C, Kleyer A, Hess A, Engelke K, David JP, Djouad F, Tuckermann JP, Desvergne B, Schett G, Kronke G (2013) PPARbeta/delta governs Wnt signaling and bone turnover. Nat Med 19(5):608-613. doi:10. 1038/nm.3146

Siri WE (1993) Body composition from fluid spaces and density: analysis of methods. Nutrition 9(5):480-491

Stefan N, Thamer C, Staiger H, Machicao F, Machann J, Schick F, Venter C, Niess A, Laakso M, Fritsche A, Haring HU (2007) Genetic variations in PPARD and PPARGC1A determine mitochondrial function and change in aerobic physical fitness and insulin sensitivity during lifestyle intervention. J Clin Endocrinol Metab 92(5):1827-1833

Stephens M, Smith NJ, Donnelly P (2001) A new statistical method for haplotype reconstruction from population data. Am J Hum Genet 68(4):978-989

Tanaka T, Yamamoto J, Iwasaki S, Asaba H, Hamura H, Ikeda Y, Watanabe M, Magoori K, Ioka RX, Tachibana K, Watanabe Y, Uchiyama Y, Sumi K, Iguchi H, Ito S, Doi T, Hamakubo T, Naito M, Auwerx J, Yanagisawa M, Kodama T, Sakai J (2003) Activation of peroxisome proliferator-activated receptor delta induces fatty acid beta-oxidation in skeletal muscle and attenuates metabolic syndrome. Proc Natl Acad Sci USA 100(26): 15924-15929

Tarnopolsky MA, Rennie CD, Robertshaw HA, Fedak-Tarnopolsky SN, Devries MC, Hamadeh MJ (2007) Influence of endurance exercise training and sex on intramyocellular lipid and mitochondrial ultrastructure, substrate use, and mitochondrial enzyme activity. Am J Physiol Regul Integr Comp Physiol 292(3):R1271-R1278

Tonkonogi M, Sahlin K (2002) Physical exercise and mitochondrial function in human skeletal muscle. Exerc Sport Sci Rev 30(3):129-137

Tudor-Locke C, Brashear MM, Johnson WD, Katzmarzyk PT (2010) Accelerometer profiles of physical activity and inactivity in normal weight, overweight and obese U.S. men and women. Int J Behav Nutr Phys Act 7:60. doi:10.1186/1479-5868-7-60

Visscher PM, Gordon S, Neale MC (2008) Power of the classical twin design revisited: II detection of common environmental variance. Twin Res Hum Genet 11(1):48-54

Wang YX, Lee CH, Tiep S, Yu RT, Ham J, Kang H, Evans RM (2003) Peroxisome-proliferator-activated receptor delta activates fat metabolism to prevent obesity. Cell 113(2):159-170

Weinsier RL, Hunter GR, Heini AF, Goran MI, Sell SM (1998) The etiology of obesity: relative contribution of metabolic factors, diet, and physical activity. Am J Med 105(2):145-150 